\title{
A Novel Micro Gripper-based Manipulation System for a Single $\mu$ LED Array
}

Jie Bai

Tiangong university

Ping-Juan Niu

Tiangong university

Gu Er-Dan ( $\sim$ erdan.gu@strath.ac.uk)

Tiangong university

Clarence-Augustine-TH Tee

University of Malaya

\section{Original Article}

Keywords: Exoskeleton arm teleoperation, Magnetic drive pump, Pneumatic force-feedback, Hybrid fuzzy control

Posted Date: August 27th, 2020

DOl: https://doi.org/10.21203/rs.3.rs-65372/v1

License: () (1) This work is licensed under a Creative Commons Attribution 4.0 International License. Read Full License 


\section{Title page}

\section{A novel micro gripper-based manipulation system for a single $\mu$ LED array}

Jie Bai, born in 1986, is currently a PhD candidate at School of Mechanical and electricity Engineering, Tiangong University, China. He received his bachelor degree from Ning Xia University, China, in 2019.

Tel: +86-15109501589; E-mail: baijie_tgu@163.com

Ping-Juan Niu, born in 1973, is currently a professor at Tiangong University, China. She received her PhD degree in TianJin University, China, in 2002.

E-mail: niupingjuan@tiangong.edu.cn

Er-Dan Gu, born in 1956, is currently a professor at Tiangong University, China. He received his PhD degree in University of Aberdeen, U.K., in 1992.

E-mail: erdan.gu@strath.ac.uk

Clarence-Augustine-TH Tee is currently a professor at Department of Electrical Engineering, University of Malaya, Malaysia. He received his $\mathrm{PhD}$ degree in University of Cambridge, U.K., in 2000.

E-mail: catht@um.edu.my

\section{Corresponding author: Er-Dan Gu E-mail: erdan.gu@strath.ac.uk}




\title{
A novel micro gripper-based manipulation system for a single $\mu$ LED array
}

\author{
Jie Bai ${ }^{1} \bullet$ Ping-Juan Niu ${ }^{1} \bullet$ Er-Dan Gu ${ }^{1} \bullet$ Clarence-Augustine-TH Tee $^{2}$
}

Received June xx, 202x; revised February xx, 202x; accepted March xx, 202x

(C) Chinese Mechanical Engineering Society and Springer-Verlag Berlin Heidelberg 2017

\begin{abstract}
LED has advantages in brightness, power consumption and response speed. In addition, $\mu$ LED can also be used as micro sensors implanted in the body via flexible electronic skin. One of the key technology is the transfer printing of $\mu$ LED. Although numerous methods have been proposed for transfer printing technology, improving the yield of $\mu$ LED array is still a formidable task. In this paper, we proposed a novel method in improving the yield of $\mu$ LED array, transferred by the stamping method, using an innovative design of piezoelectric driven asymmetric micro gripper. A $\mu$ LED manipulation system was constructed based on a micro gripper of a three dimensional positioning system. The experimental results showed that this system could be used to manipulate $\mu$ LED array.
\end{abstract}

Keywords: Exoskeleton arm teleoperation • Magnetic drive pump

- Pneumatic force-feedback • Hybrid fuzzy control

\section{Introduction}

In recent years, Apple, Samsung, SONY, and other companies have initiated the research of $\mu \mathrm{LED}$ technology [1 2], which has the potential as a technology enabler for the display in smart devices, charting a new way forward and disruptive direction for the display technology roadmap [3 4].

$\mu \mathrm{LED}$ is the LED technology of miniaturization and matrixing, which is used to integrate high-density and micro-sized LED arrays on a chip, with pixel size generally

Er-Dan Gu

erdan.gu@strath.ac.uk

1 School of Mechanical and electricity Engineering, Tiangong University, Tianjin 300387, People' s Republic of China

2 Department of Electrical Engineering, Faculty of Engineering, University of Malaya, Kuala Lumpur 50603, Malaysia less than $100 \mu \mathrm{m}$. The surface morphology of the $\mu \mathrm{LED}$ is observed with a field emission scanning electron microscope (ZEISS SIGMA 300), as shown in Fig.1.

The main advantage of $\mu$ LED is that each pixel cell can be individually controlled and driven. Its brightness, contrast ratio, power dissipation, resolution, and other parameters are superior and have met the standard requirement with its characteristics of micron pixel spacing. $\mu \mathrm{LED}$ is brighter even under the low power conditions as compared to other competing technologies. In other words, it consumes $90 \%$ less power than LCD and 50\% less than OLED but emitting the same brightness. Accordingly, if smart phones are using $\mu$ LED displays, the battery life would be greatly improved, which is critical for portable devices. Furthermore, the response time of $\mu$ LED is in the range of nanosecond. Its quick response time is faster in comparison to the response times of LCD (in millisecond range) and the OLED (in microsecond range), making it the best choice for virtual reality (VR) application of $5 \mathrm{G}$ technology [2]. In another words, $\mu$ LED technology would lead the trend as the technology enabler for display applications in the $5 \mathrm{G}$ era [3].

There are two ways to integrate $\mu \mathrm{LED}$ crystalline grains into displays. The $1^{\text {st }}$ method is the wafer bonding method using a monomer manufacturing process. In this method, the $\mu$ LED array is fabricated by etching the LED chip, and then the $\mu \mathrm{LED}$ array is directly assembled with the triode backplane to form a single display device. This method can be used to fabricate small size matrix addressable monolithic integrated LED display devices, such as those in VR glasses. The high density, high resolution and low pixel size display devices can be made in this way. However, this method is difficult to be applied in the manufacturing of large area display devices due to the issues such as the 

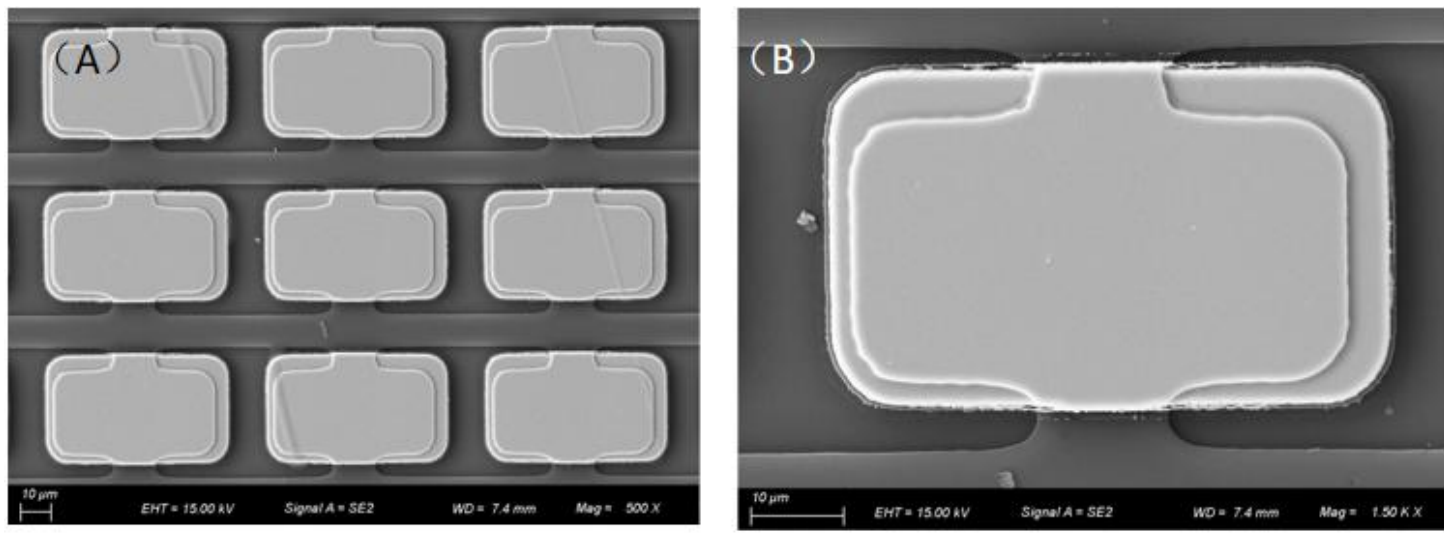

(C)
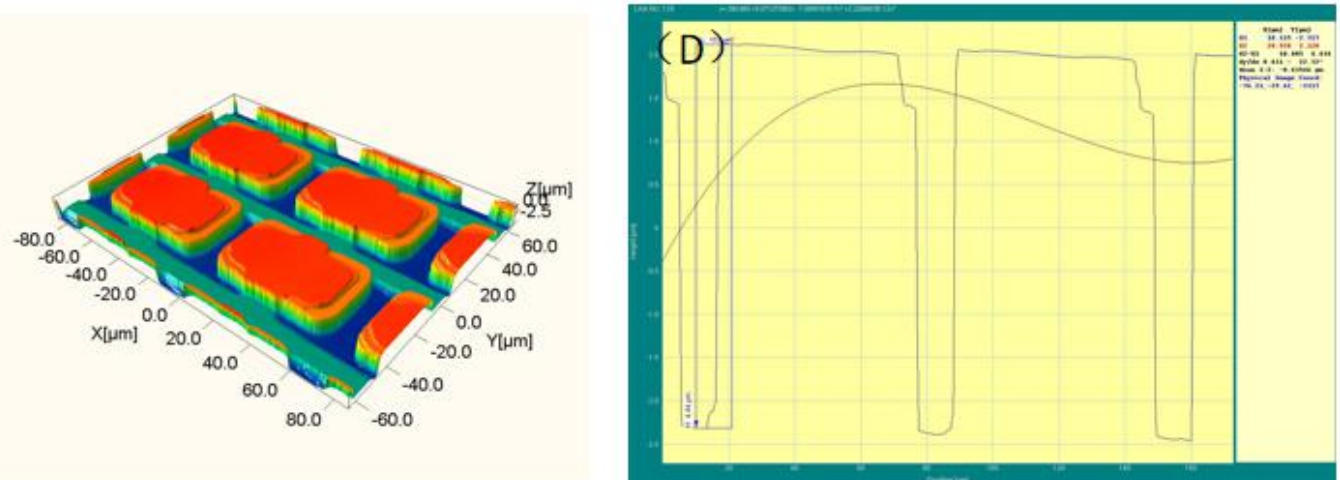

Figure 1. The image of an array of $\mu \mathbf{L E D}$; (A) and (B) are the SEM images of $\mu \mathrm{LED}$ with the magnification of 500x and 1.5Kx; (C) and (D) are the surface texture of $\mu$ LED array captured by a white light interferometer.

limited size of LED chip, any damaged pixels cannot be repaired, and there is a mismatch of the sizes of the donor and display arrays.

The $2^{\text {nd }}$ method is the grain bonding method based on $\mu$ LED crystalline transfer printing. In this method, discrete grains are picked up and placed precisely on a rigid or flexible backplane, and connected later with the driving integrated circuit (IC) to form a display device. Compared with wafer bonding method, this method can be used to fabricate large area display devices in the range of several inches to dozens of inches, such as TV and mobile phones [4]. Stamp method [5 14], roller method [15 19], laser method [20 22], electrostatic method [22 27], magnetoelectric method [28] and fluid method [29 31] are commonly used to transfer $\mu \mathrm{LED}$. Among them, the most commonly used is the stamp method. The stamp method is a technology in which the $\mu$ LED array is picked up and transferred to the target substrate in parallel by a seal of microstructures. X-Celeprint [5] has proposed the use of polydimethylsiloxane (PDMS) materials to produce a large amount of elastic stamps. In this transfer method, the absorption and release of the $\mu \mathrm{LED}$ is achieved by controlling the speed of the stamp. When the stamp moves faster, $\mu$ LEDs are adsorbed to the stamp due to the van der Waals force. When the movement speed of the stamp is slow, the $\mu$ LEDs detach from the micro-stamp and are adsorbed to the receiving substrate. The Korea Institute of Machining and Materials has proposed a transfer technology based on barrel seals [15 19]. The transfer speed of this method can reach 10,000 grains per second.

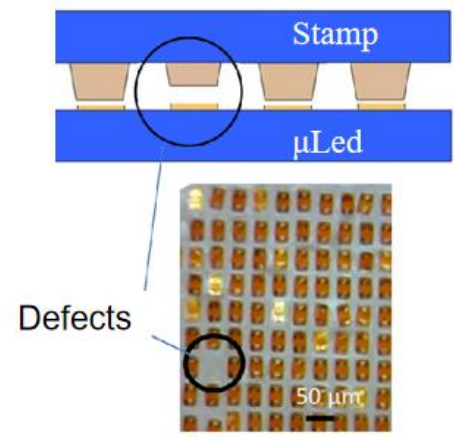

Figure 2. The mismatch error associated with the stamp method

However, the roughness of stamp surface and donor substrate will lead to large mismatch error as shown in Fig. 2. Also, the local temperature inhomogeneity could contribute to mismatch error too. The thermal coefficient of 
PDMS is about $340 \mathrm{ppm} /{ }^{\circ} \mathrm{C}$, while the thermal coefficient of the donor substrate $(\mathrm{Si})$ is about $5 \sim 9 \mathrm{ppm} /{ }^{\circ} \mathrm{C}$. There would be a mismatch error of $33 \mu \mathrm{m}$ between the stamp and the $\mu$ LED array for the stamp with a side length of $100 \mathrm{~mm}$ if the ambient temperature changes by $1{ }^{\circ} \mathrm{C}$. Thus, contributing to a low yield rate of stamp transfer printing. In view of the issue that the stamp transfer printing has a low yield rate, we propose herewith, a micro-holder [32 33] to manipulate the $\mu$ LED array in improving the yield of the micro-stamp transfer.

\section{The gripper-based manipulative system for $\mu$ LED}

Due to the limited size of $\mu$ LED crystal, it is necessary to design a mechanical gripper to handle $\mu$ LED. Mechanical clamping is a mechanical structure-based clamping method with a superior advantage in comparison to other clamping methods i.e. it can be used in conjunction with a microscopic camera to perform the repair of a $\mu$ LED. Fig. 3 shows an asymmetric micro gripper [34 36] driven by piezoelectricity in repairing the bad points due to transfer printing of $\mu$ LED crystals.

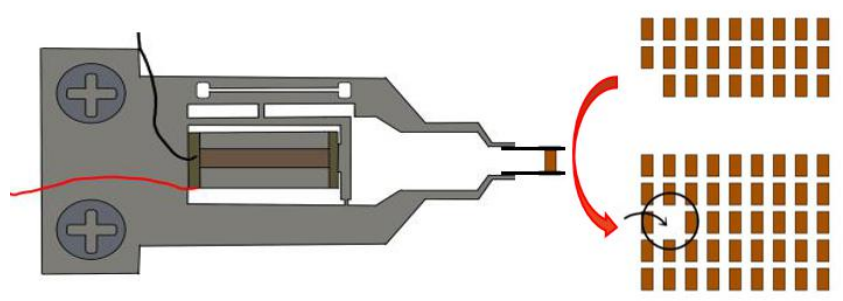

Figure 3. Schematic diagram of a gripper-based $\mu$ LED manipulate system.

\subsection{Design of the gripper}

The micro gripper can be used to carry out micro operation of an object such as clamping, transfering, releasing and other operative tasks. Recent literature reviews show that some earlier work on gripper has been done by numerous scientists in recent years [37 39]. In Fig. 4 (A), we proposed our design structure of our gripper based on the asymmetric clamping mode. The clamping arm on one side is fixedly attached to the frame of the gripper. The clamping arm on the other side is directly connected with the lever mechanism per the output end of the gripper. This structure ensures the stability during clamping and avoids the instability caused by manufacturing error. At the same time, it reduces the difficulty of operation. In practical operation, only a piezoelectric drive is needed to control the displacement of a clamping arm to clip the object.

The clamping arm of the micro-gripper moves in a translational mode. In this translational movement mode, the two clamping arms are always in a parallel direction. When the clamping arms move in parallel, the Y-direction component force generated by the system is extremely small, so the Y-direction displacement is approximately equal to zero. This ensures that when the gripper clamps the object, even if it is interfered by the external forces, the clamped object will not slip off. In addition, this gripper uses a parallelogram mechanism for the final stage as an amplifying mechanism. When the rotation angle of the parallelogram mechanism is small, the displacement generated by the system in the horizontal direction is much greater than the displacement generated in the vertical direction. The relationship between vertical displacement and rotation angle is as follows:

$$
\mathrm{y}=l(1-\cos \theta)
$$

where $\mathrm{y}$ is the vertical displacement generated, $l$ is the length of the moving part of the parallelogram mechanism, and $\theta$ is the angle that the parallelogram mechanism rotates. According to equation (1), it can be seen that when the turning angle is extremely small, $\cos \theta$ is close to 1 , resulting in a vertical displacement close to 0 at that moment. The parallelogram mechanism is directly connected with the output end of the micro-gripper, which ensures the parallel movement of the clamping end of the micro-gripper.

This micro-gripper is driven by stacked of piezoelectric ceramics where the output displacement of the gripper depends on the input displacement of the piezoelectric ceramics. We simulated the displacement amplification ratio of different depths by finite element method as shown in Fig. 4(B).

Table 1 The displacement amplification of gripper

\begin{tabular}{ccccc}
\hline Input & $\mathrm{X}$ & $\mathrm{Y}$ & $\mathrm{Y} / \mathrm{X}$ & $\begin{array}{c}\text { Displacement } \\
\text { amplification ratio }\end{array}$ \\
$(\mu \mathrm{m})$ & $(\mu \mathrm{m})$ & $(\mu \mathrm{m})$ & & 10.219 \\
\hline 2 & 20.438 & 0.183 & 0.00895 & 10.219 \\
4 & 40.876 & 0.367 & 0.00899 & 10.219 \\
6 & 61.313 & 0.551 & 0.00897 & 10.219 \\
\hline 8 & 81.751 & 0.734 & 0.00898 & 10.22 \\
\hline
\end{tabular}



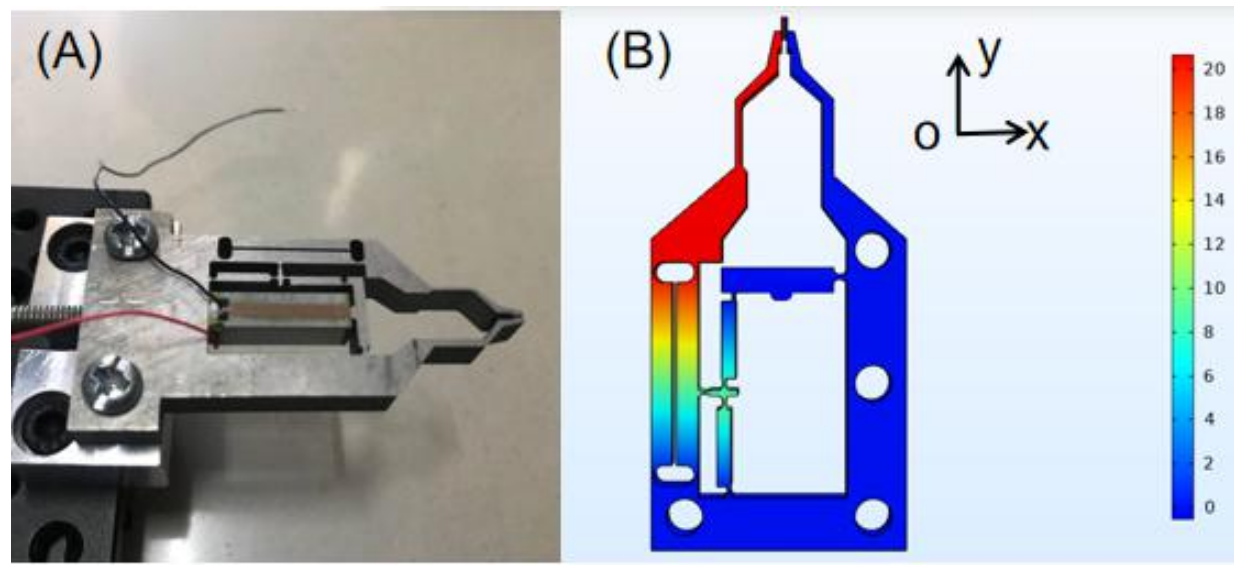

Figure 4. Micro gripper. (A) Image of gripper. (B) Model of the gripper by finite element simulation.

In order to simulate the output of the gripper, the input displacements are set at the positions of piezoelectric ceramic as: $2 \mu \mathrm{m}, 4 \mu \mathrm{m}, 6 \mu \mathrm{m}, 8 \mu \mathrm{m}$ and $10 \mu \mathrm{m}$. The $\mathrm{X}$ and $\mathrm{Y}$ displacements of the movable clamping arm of the micro-gripper under different inputs are recorded as shown in Tab. 1. The results show that the displacement of $\mathrm{Y}$ direction is much less than that of $\mathrm{X}$ direction. The displacement amplification ratio of this gripper is about 10.2 .

\subsection{Design of the gripper tip}

The distance between the two clamping arms of the gripper and the size of the clamping arm are much larger than the size of the $\mu$ LED crystal. In order to meet the needs of $\mu$ LED crystal clamping and transfer, two sets of micro-sized cantilever are added at the tip of the gripper. The selection of the size of the cantilever beam is extremely important.

The stress, introduced by the cantilever when clamping the $\mu \mathrm{LED}$ crystal, needs to be assessed, in ensuring that the clamping end will not damage the $\mu$ LED during the clamping process. According to Euler's formula, the thickness of the cantilever has the greatest influence on the magnitude of the stress introduced by the micro-gripper. Therefore, finite element method is used to simulate the stress conditions of cantilever with different thicknesses when holding and transferring $\mu$ LED crystals.

Considering the size of the $\mu$ LED crystal, the length of the cantilever is set at $100 \mu \mathrm{m}$ and the width at $30 \mu \mathrm{m}$. The micro-gripper models the cantilever beams with thicknesses of $0.5 \mu \mathrm{m}, 1 \mu \mathrm{m}$ and $1.5 \mu \mathrm{m}$ are established respectively. The maximum force at the movable end-clamping is simulated under different input displacements at the simulation input end. Accordingly, the working ranges of cantilever with different thicknesses are determined. The simulation experiment data is shown in Fig. 5.

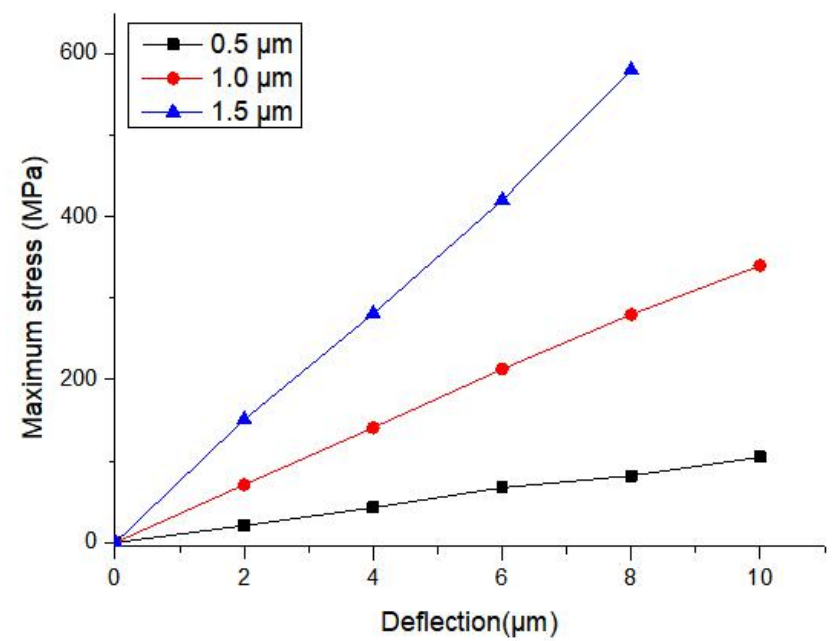

Figure. 5 Simulation diagram of the force at the tip of the gripper

The yield strength of this material used for the micro-gripper is $503 \mathrm{MPa}$. The simulation results show that the maximum stress that the cantilever with thicknesses of $0.5 \mu \mathrm{m}$ and $1 \mu \mathrm{m}$ could bear in the whole working range. The max stress will not exceed the yield strength of the gripper material. This means that even in extreme cases, due to excessive stress, the clamping end of the micro-gripper will not damage the $\mu$ LED.

For a cantilever with a thickness of $1.5 \mu \mathrm{m}$, when the input displacement is $8 \mu \mathrm{m}$, the max stress will exceed the yield strength and cause damage. Although the clamping cantilever with a thickness of $1.5 \mu \mathrm{m}$ will be damaged in the extreme case where the $\mu$ LED crystal is immovable, the irreversible damage will only occur when the input displacement reaches $7.5 \mu \mathrm{m}$. And in actual operation, the driving voltage applied to the piezoelectric ceramic end of 
the micro-gripper increases slowly from low to high. Therefore, it can be considered that the cantilever with a thickness of $1.5 \mu \mathrm{m}$ performs well under extreme conditions and will not cause any damages. From the above analysis, it can be determined that the ideal thickness of the cantilever of the micro-gripper should be $1.5 \mu \mathrm{m}$.

\section{Experimental result}

\subsection{The characteristics of micro gripper}

In order to investigate the performance characteristics of micro gripper, the voltages at both ends of the piezoelectric ceramic are applied from 0 to $120 \mathrm{~V}$ with an amplification of $10 \mathrm{~V}$. The input voltage is converted into the corresponding input displacement of piezoelectric ceramics. At the same time, the output displacement of the micro gripper is measured. The ratio of the output displacement of the clamping arm to the input displacement of the piezoelectric ceramic is the amplification factor of the gripper. Some of the data are shown in Tab. 2.

Table 2. Amplification factor test

\begin{tabular}{ccc}
\hline $\begin{array}{c}\text { Input } \\
\text { voltage(V) }\end{array}$ & $\begin{array}{c}\text { Input displacement } \\
(\mu \mathrm{m})\end{array}$ & $\begin{array}{c}\text { Output displacement } \\
(\mu \mathrm{m})\end{array}$ \\
\hline 0 & 0 & 0 \\
20 & 2.67 & 21.31 \\
40 & 5.33 & 42.78 \\
60 & 8.0 & 59.38 \\
80 & 10.67 & 80.23 \\
100 & 13.33 & 94.86 \\
120 & 16.0 & 112.63 \\
\hline
\end{tabular}

The experimental results show that the displacement amplification ratio of the micro gripper is about 7.5.

\section{2 $\mu$ LED clamping experiment}

The experimental setup of the clamping experiment is shown in Fig. 6(A), which is composed of three parts: micro gripper, depth of field of the three-dimensional microscope system and the adjustment table. The depth of field of the $3 \mathrm{D}$ microscope system can be observed and the experimental images can be saved in real time while recording the clamping process.

In order to investigate the performance of the manipulation system, the $\mu \mathrm{LED}$ is used in the experiment as shown in Fig. 1. The $\mu$ LED has small size with a length of $40 \mu \mathrm{m}$, a width of $20 \mu \mathrm{m}$ and a thickness of $4 \mu \mathrm{m}$. A single $\mu \mathrm{LED}$ is manipulated by a gripper as shown in Fig. 6 (B). The optical image of ' $\mathrm{T}$ ' pattern assembled with $\mu$ LEDs by the micro gripper is shown in Fig. 6 (C). It can be seen that the micro gripper achieves a stable clamping state. Meanwhile, it is found that the y-direction position difference of the two clamping arms before and after clamping is very small, enables a parallel clamping. The micro gripper in this research is designed with one side of the clamping arm fixed and the other side movable. The fixed clamping arm is used as the positioning reference in the experiment. It greatly reduces the positioning time and improves the experimental efficiency.

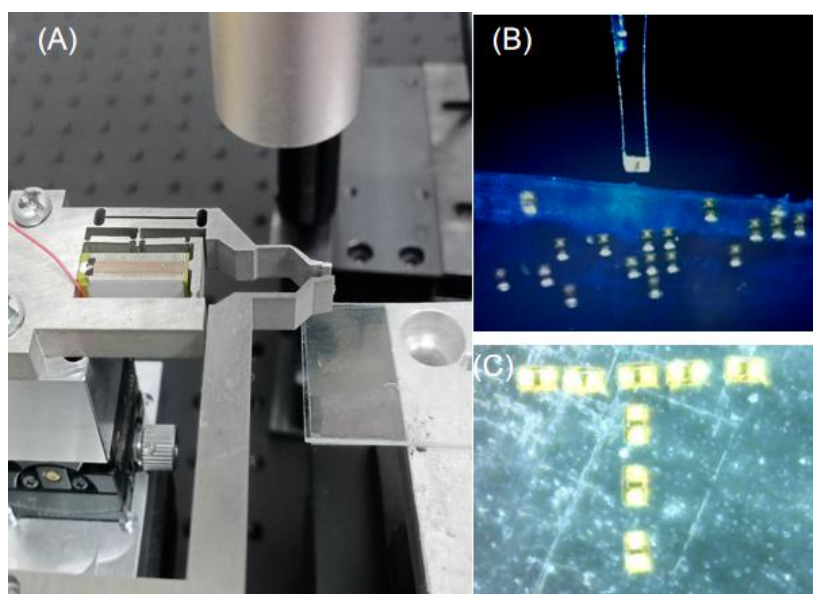

Figure. 6 Micromanipulation of $\boldsymbol{\mu L E D}$ by gripper. (A) The $\mu$ LED micromanipulation system (B) A single $\mu$ LED is manipulated by the micro gripper. (C) Optical image of the $\mu$ LEDs in ' $T$ 'pattern, assembled by micro gripper.

\section{Conclusions}

The existing $\mu$ LED handling and transferring mechanisme has the limitation of low yield. In this paper, the micro gripper is used to manipulate and transfer $\mu$ LED array with improved yield. The next step would be to leverage on the work done here and design a new method in repairing $\mu$ LED array using the inherent low speed of the manipulation system, herewith. Thus, our next step would be to incorporate this methodology to industrial scale research work.

\section{Declaration}

\section{Acknowledgements}

The authors sincerely thanks to Professor Yanling Tian of TianJin University for his critical discussion and reading during manuscript preparation. 


\section{Funding}

Supported by Tianjin science and technology support major project (Grant No 18ZXCLGX00090).

\section{Availability of data and materials}

The datasets supporting the conclusions of this article are included within the article.

\section{Authors' contributions}

The author' contributions are as follows: Ping-Juan Niu and Er-Dan $\mathrm{Gu}$ was in charge of the whole trial; Jie Bai wrote the manuscript; Clarence-Augustine-TH Tee assisted with sampling and laboratory analyses.

\section{Competing interests}

The authors declare no competing financial interests.

\section{Consent for publication}

Not applicable

\section{Ethics approval and consent to participate}

Not applicable

\section{References}

[1] Zheng Yelong, Song Le, Huang Jingxiong, Zhang Haoyang, Fang Fengzhou. Detection of the three-dimensional trajectory of an object based on a curved bionic compound eye. OPTICS LETTERS, 2019,44(17): 4143-4146.

[2]C.W. Jeon, H.W. Choi, M.D. Dawson. Fabrication of matrix-addressable InGaN-based microdisplays of high array density. IEEE Photon. Technol. Lett., 15 (2003), pp. 1516-1518 [3]Z. Liu, K.M. Wong, W.C. Chong, K.M. Lau. Active matrix programmable monolithic light emitting diodes on silicon (LEDoS) displays. SID Symposium Digest of Technical Papers, 42 (2011), pp. 1215-1218,

[4]Z.B. Kamarei. Analysis for science librarians of the 2014 Nobel Prize in physics: invention of efficient blue-light-emitting diodes. Sci. Technol. Libr., 34 (2015), pp. 19-31,

[5]S.-I. Park, Y. Xiong, R.-H. Kim, P. Elvikis, M. Meitl, D.-H. Kim, J. Wu, J.Yoon, C.-J. Yu, Z. Liu, Y. Huang, K.-C. Hwang, P. Ferreira, X. Li, K.Choquette, J.A. Rogers. Printed assemblies of inorganic light-emitting diodes for deformable and semitransparent displays. Science, 325 (2009), pp. 977-981
[6]R.S. Cok, M. Meitl, R. Rotzoll, G. Melnik, A. Fecioru, A.J. T rindade, B.Raymond, S. Bonafede, D. Gomez, T. Moore, C. Pre vatte, E. Radauscher, S.Goodwin, P. Hines, C.A. Bower. Inorganic light-emitting diode displays using micro-transfer printing. J. Soc. Inf. Disp., 25 (2017), pp. 589-609

[7]T.-I. Kim, Y.H. Jung, J. Song, D. Kim, Y. Li, H.-S. Kim, I.-S.

Song, J.J. Wierer, H.A. Pao, Y. Huang, J.A. Rogers. High-efficiency, microscale GaN light-emitting diodes and their thermal properties on unusual substrates. Small, 8 (2012), pp. 1643-1649

[8]

A. Carlson, A.M. Bowen, Y. Huang, R.G. Nuzzo, J.A. Rogers. Transfer printing techniques for materials assembly and micro/nanodevice fabrication. Adv. Mater., 24 (2012), pp. $5284-5318$

[9]S. Kim, J. Wu, A. Carlson, S.H. Jin, A. Kovalsky, P. Glass, Z. Liu, N. Ahmed, S.L. Elgan, W. Chen, P.M. Ferreira, M. Sitti, Y. Huang, J.A. Rogers. Microstructured elastomeric surfaces with reversible adhesion and examples of their use in deterministic assembly by transfer printing. Proc. Natl. Acad. Sci. Unit. States Am., 107 (2010), pp. 17095-17100

[10] H.-H. Hu, K.K.C. Chang, A. Bibl, Micro Device with Stabilization Post: U.S. Patent 9209348 [P]. 12/08/2015.

[11]A.J. Trindade, B. Guilhabert, E.Y. Xie, R. Ferreira, J.J.D. M cKendry, D. Zhu, N. Laurand, E. Gu, D.J. Wallis, I.M. Watson, C.J. Humphreys, M.D. Dawson. Heterogeneous integration of gallium nitride light-emitting diodes on diamond and silica by transfer printing. Optic Express, 23 (2015), pp. 9329-9338 [12]M.A. Meitl, Z.-T. Zhu, V. Kumar, K.J. Lee, X. Feng, Y.Y. Huang, I. Adesida, R.G. Nuzzo, J.A. Rogers. Transfer printing by kinetic control of adhesion to an elastomeric stamp. Nat. Mater., 5 (2006), pp. 33-38

[13]X. Feng, M.A. Meitl, A.M. Bowen, Y. Huang, R.G. Nuzzo, J.A. Rogers. Competing fracture in kinetically controlled transfer printing. Langmuir, 23 (2007), pp. 12555-12560

[14]Y.Y. Huang, W. Zhou, K.J. Hsia, E. Menard, J.-U. Park, J.A. Rogers, A.G.Alleyne. Stamp collapse in soft lithography. Langmuir, 21 (2005), pp. 8058-8068

[15]S. Bae, H. Kim, Y. Lee, X. Xu, J.-S. Park, Y. Zheng, J. Bala krishnan, T. Lei, H.R. Kim, Y.I. Song, Y.-J. Kim, K.S. Kim, B.

Ö zyilmaz, J.-H. Ahn, B.H.Hong, S. Iijima. Roll-to-roll 
production of 30-inch graphene films for transparent electrodes.

Nat. Nanotechnol., 5 (2010), p. 574

[16]M.H. Lee, N. Lim, D.J. Ruebusch, A. Jamshidi, R. Kapadia,

R. Lee, T.J. Seok, K. Takei, K.Y. Cho, Z. Fan, H. Jang, M. Wu,

G. Cho, A. Javey. Roll-to-roll anodization and etching of aluminum foils for high-throughput surface nanotexturing. Nano Lett., 11 (2011), pp. 3425-3430

[17]L. Tavares, J. Kjelstrup-Hansen, H.-G. Rubahn. Efficient roll-on transfer technique for well-aligned organic nanofibers. Small, 7 (2011), pp. 2460-2463

[18]Y. Yang, Y. Hwang, H.A. Cho, J.-H. Song, S.-J. Park, J.A. Rogers, H.C. Ko. Arrays of silicon micro/nanostructures formed in suspended configurations for deterministic assembly using flat and roller-type stamps. Small, 7 (2011), pp. 484-491

[19]V. Marinov, O. Swenson, R. Miller, F. Sarwar, Y. Atanasov, M. Semler, S. Datta. Laser-enabled advanced packaging of ultrathin bare dice in flexible substrates. IEEE Trans. Compon. Packag. Manuf. Technol., 2 (2011), pp. 569-577, 10.1109/TCPMT.2011.2176941

[20]R. Miller, V. Marinov, O. Swenson, Z. Chen, M. Semler. Noncontact selective laser-assisted placement of thinned semiconductor dice. IEEE Trans. Compon. Packag. Manuf. Technol., 2 (2012), pp. 971-978, 10.1109/TCPMT.2012.2183594

[21]K. Tomoda, Method of Transferring a Device Amd Method of Manufacturing a Display Apparatus: U.S. Patent 12/647826 [P]. 07/29/2010.

[22]A. Bibl, J.A. Higginson, H.-F.S. Law, H.-H. Hu, Method of Transferring a Micro Device: U.S. Patent 8333860 [P]. $12 / 18 / 2012$.

[23]A. Bibl, J.A. Higginson, H.-F.S. Law, H.-H. Hu, Micro-LED Transfer Head Heater Assembly and Method of Transferring a Micro-LED: U.S. Patent 8349116 [P]. 01/08/2013.

[24]A. Bibl, D. Golda, Micro Pick up Array with Compliant Contact: U.S. Patent 9136161 [P]. 09/15/2015.

[25]H.-H. Hu, A. Bibl, Stabilization Structure Including Sacrificial Release Layer and Staging Cavity: U.S. Patent 9166114 [P]. 10/20/2015.

[26]K.V. Sakariya, A. Bibl, H.-H. Hu, Active Matrix Display Panel with Ground Tie Lines: U.S. Patent 9559142 [P]. $01 / 31 / 2017$.
[27]A. Bibl, D. Golda, Compliant micro device transfer head with integrated electrode leads: U.S. Patent 8791530 [P]. $07 / 29 / 2014$

[28]L.-Y. Chen, H.-W. Lee, Method for Transferring Semiconductor Structure: U.S. Patent 9722134 [P]. 08/01/2017.

[29]H.O. Jacobs, Method of Self-Assembly on a Surface: U.S. Patent 7774929 [P]. 08/17/2010.

[30]J.J. Jacobsen, G.W. Gengel, G.S.W. Craig, Methods for Fabricating a Multiple Modular Assembly: U.S. Patent 6316278 [P]. 11/13/2001.

[31]P.J. Schuele, K. Sasaki, K. Ulmer, J.-J. Lee, Display with Surface Mount Emissive Elements: U.S. Patent 15/410001 [P]. $05 / 11 / 2017$.

[32]Cunman Liang, Fujun Wang, Beichao Shi, Zhichen Huo, Kaihuan Zhou, Yanling Tian, Dawei Zhang, Design and control of a novel asymmetrical piezoelectric actuated microgripper for micromanipulation, Sensors and Actuators: A-Physical, 2018, A269: 227-237.

[33]Sun X, Chen W, Tian Y, et al. A novel flexure-based microgripper with double amplification mechanisms for micro/nano manipulation. Review of Scientific Instruments, 2013, 84(8):085002.

[34]Nobuyuki I , Takashi K . Large deformation analysis and synthesis of elastic closed-loop mechanism made of a certain spring wire described by free curves. Chinese Journal of Mechanical Engineering, 2015, 28(004):756-762.

[35]Zhong Chen. Design and experimental study of compliant structural force cell based on digital image correlation. Chinese Journal of Mechanical Engineering, 2013, 49(9):12.

[36]Jinkui C, Xiuchun H, Liding W. Design and fabrication of electrothermal nickel microgripper. Chinese Journal of Mechanical Engineering, 2007,43(5): 116-121.

[37]Sun X, Chen W,Tian Y, et al. A novel flexure-based microgripper with double amplification mechanisms for micro/nano manipulation. The Review of scientific instruments, 2013, 84(8).

[38] Zheng Y, Song L, Hu G, et al. Improving environmental noise suppression for micronewton force sensing based on electrostatic by injecting air damping. Review of Scientific Instruments, 2014, 85(5): 055002.

[39]Cunman Liang, Fujun Wang, Beichao Shi, Zhichen Huo, Kaihuan Zhou, Yanling Tian, Dawei Zhang. Design and control of a novel asymmetrical piezoelectric actuated microgripper for 
micromanipulation, Sensors and Actuators: A-Physical, 2018, A269: 227-237.

\section{Biographical notes}

Jie Bai, born in 1986, is currently a $\mathrm{PhD}$ candidate at School of Mechanical and electricity Engineering, Tiangong University, China. He received his bachelor degree from Ning Xia University, China, in 2019.

Tel: +86-15109501589; E-mail: baijie_tgu@163.com

Ping-Juan Niu, born in 1973, is currently a professor at Tiangong University, China. She received her $\mathrm{PhD}$ degree in TianJin University, China, in 2002.

E-mail: niupingjuan@tiangong.edu.cn

Er-Dan Gu, born in 1956, is currently a professor at Tiangong University, China. He received his $\mathrm{PhD}$ degree in University of Aberdeen, U.K., in 1992.

E-mail: erdan.gu@strath.ac.uk

Clarence-Augustine-TH Tee is currently a professor at Department of Electrical Engineering, University of Malaya, Malaysia. He received his $\mathrm{PhD}$ degree in University of Cambridge, U.K., in 2000.

E-mail: catht@um.edu.my 


\section{Figures}
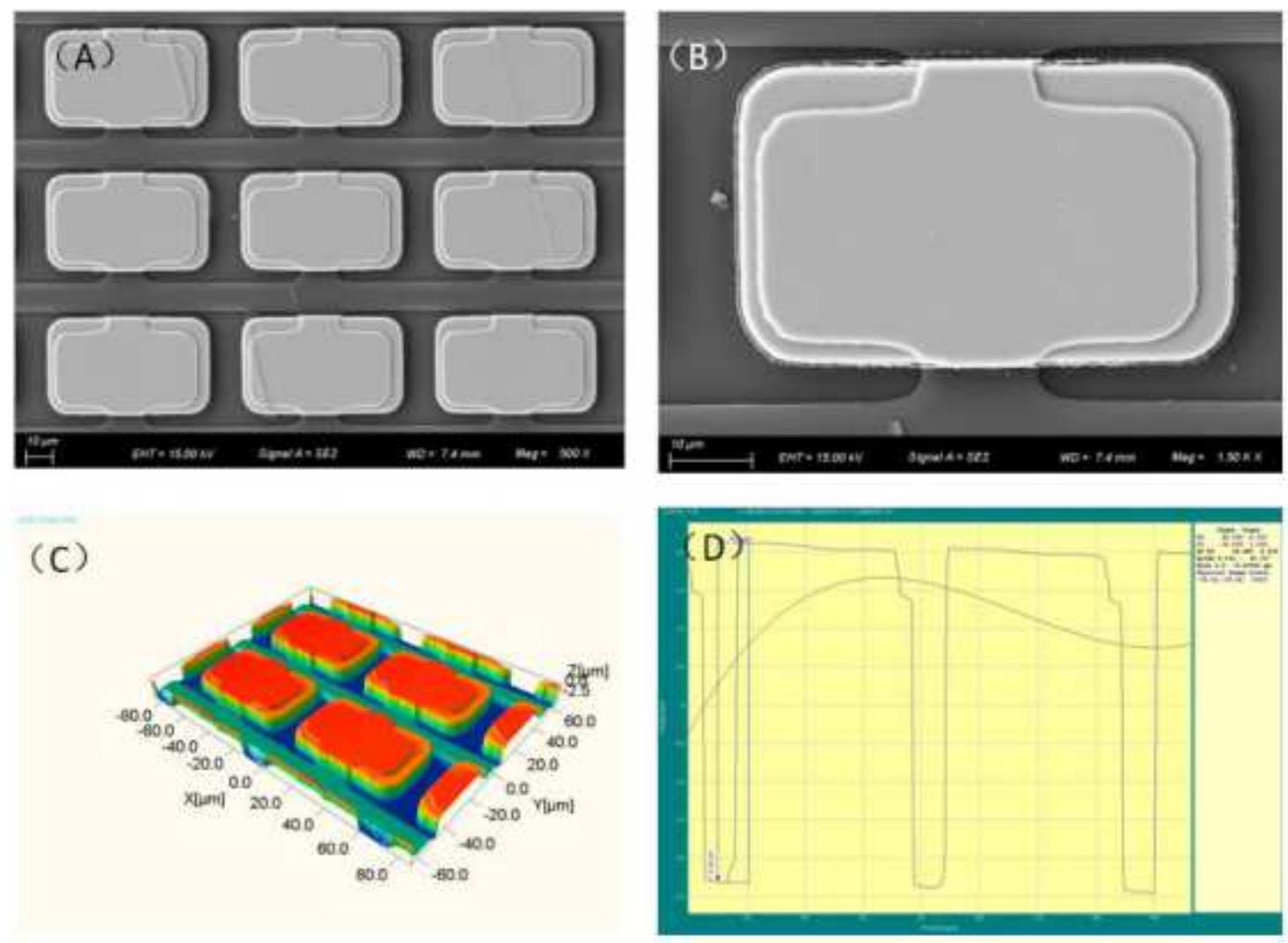

\section{Figure 1}

The image of an array of $\mu$ LED; (A) and (B) are the SEM images of $\mu$ LED with the magnification of $500 x$ and $1.5 \mathrm{Kx} ;(C)$ and $(D)$ are the surface texture of $\mu \mathrm{LED}$ array captured by a white light interferometer.

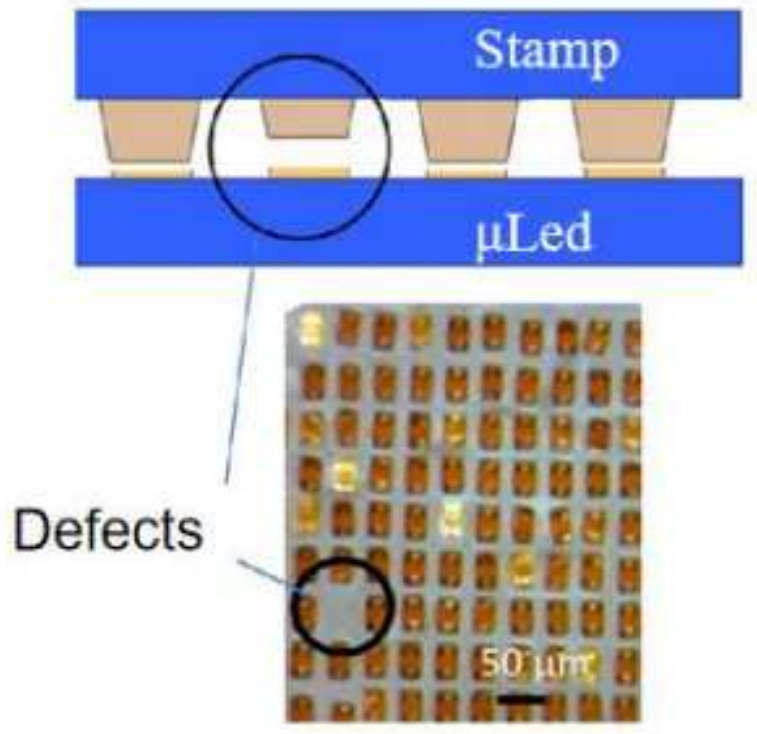

Figure 2 


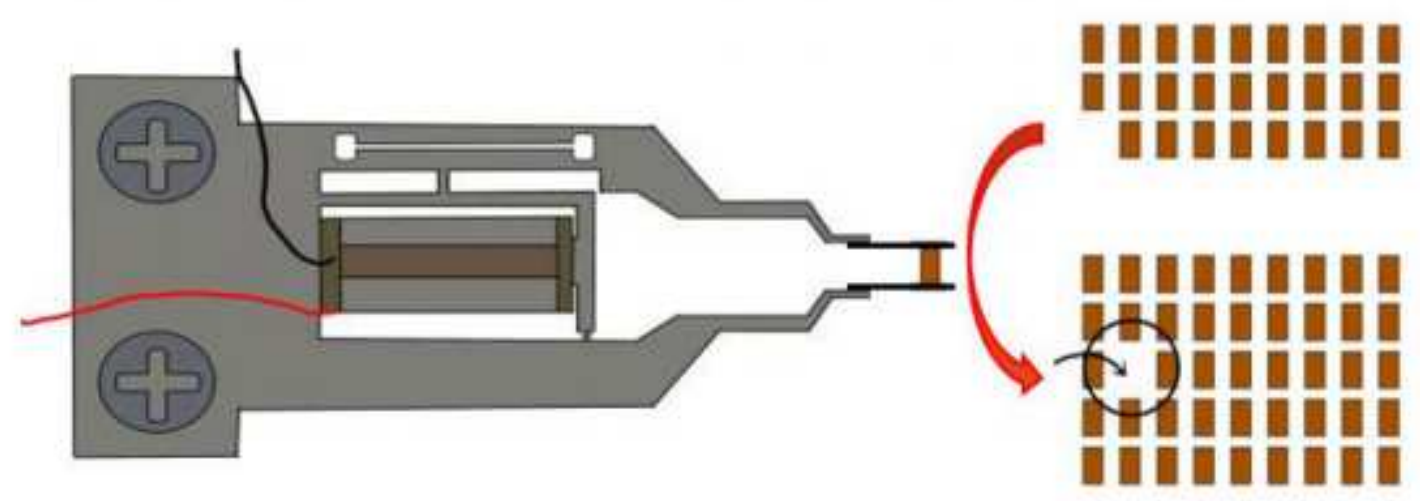

Figure 3

Schematic diagram of a gripper-based $\mu$ LED manipulate system.
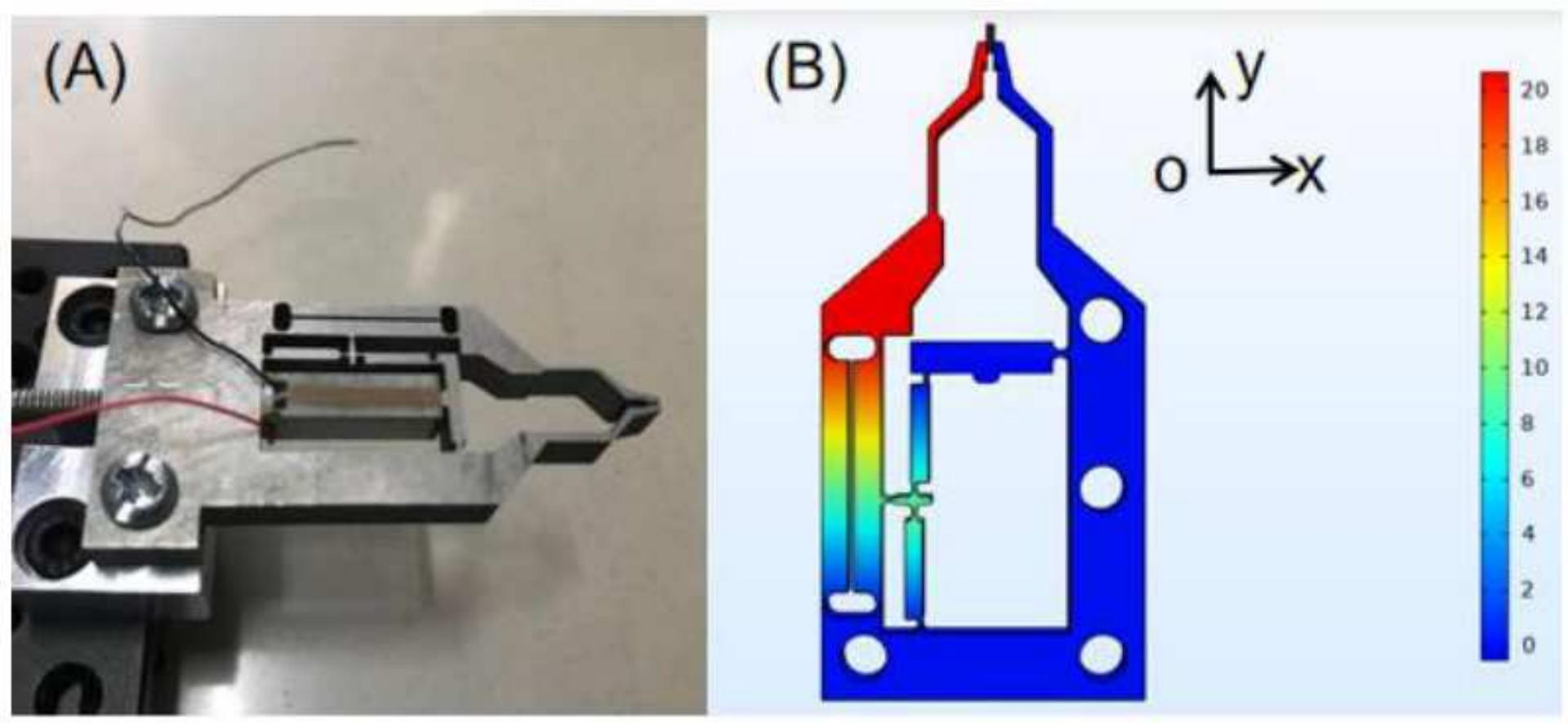

Figure 4

Micro gripper. (A) Image of gripper. (B) Model of the gripper by finite element simulation 


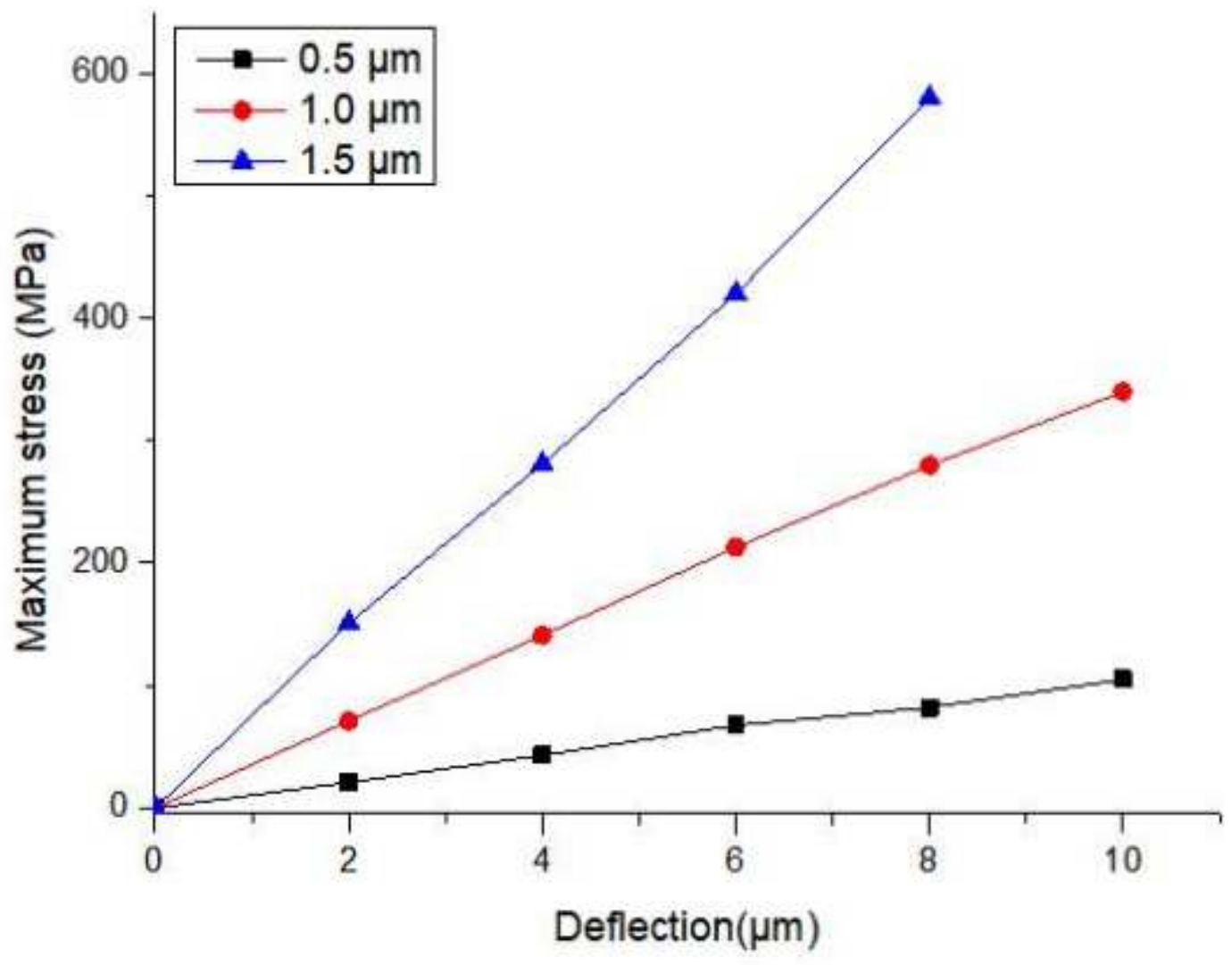

Figure 5

Simulation diagram of the force at the tip of the gripper

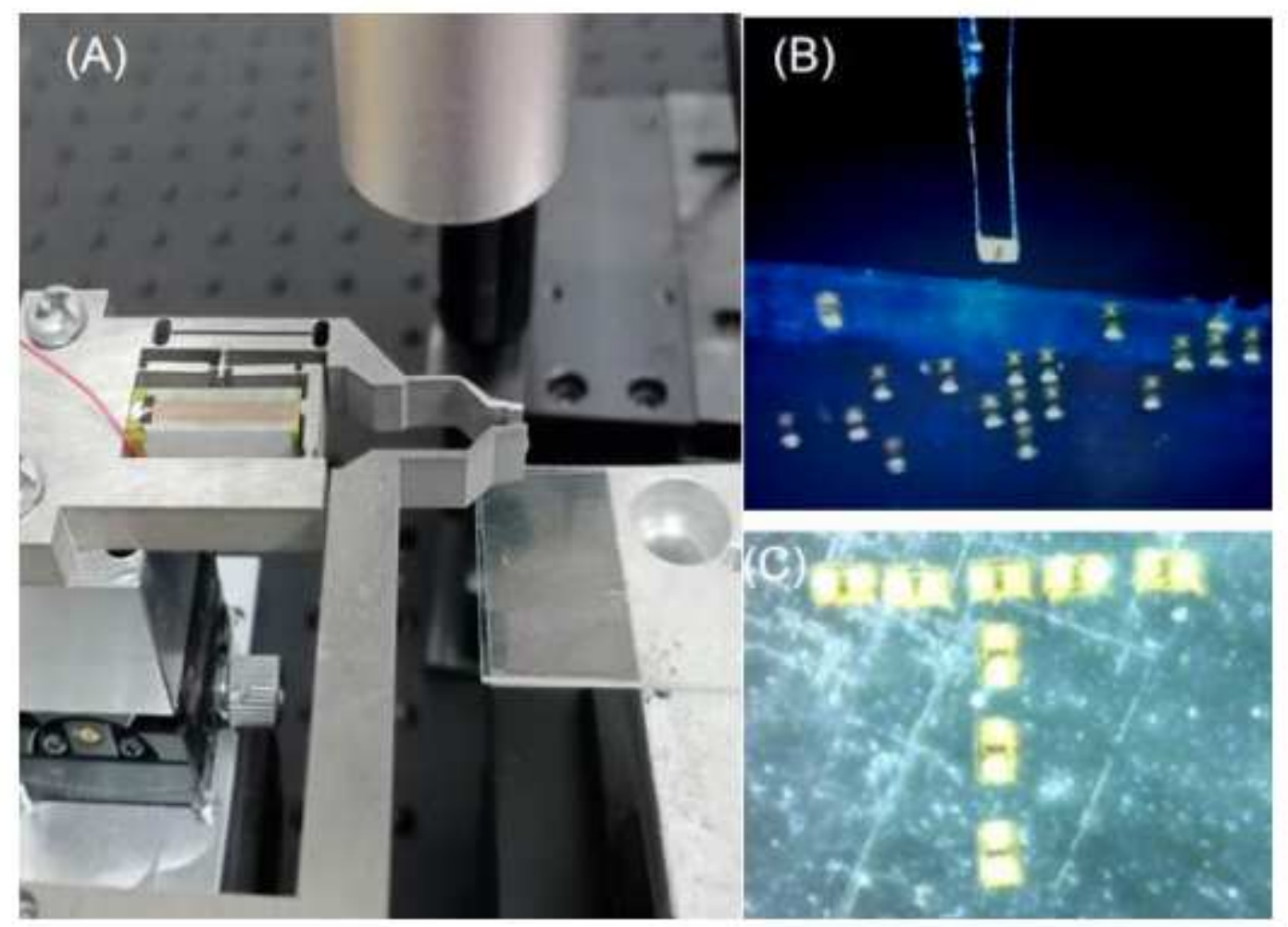

Figure 6 
6 Micromanipulation of $\mu$ LED by gripper. (A) The $\mu$ LED micromanipulation system (B) A single $\mu L E D$ is manipulated by the micro gripper. (C) Optical image of the $\mu \mathrm{LEDs}$ in 'T'pattern, assembled by micro gripper. 